Amanda de Paula Boni Navarro (iD https://orcid.org/0000-0002-6593-0669

Marcos Claudio Signorellib (D) https://orcid.org/0000-0003-0677-0121

Guilherme Souza Cavalcanti de

Albuquerque $^{\mathrm{b}}$

(iD) https://orcid.org/0000-0002-7544-412X

a Secretaria de Estado da Saúde do Paraná, Centro Estadual de Saúde do Trabalhador. Curitiba, PR, Brasil.

b Universidade Federal do Paraná (UFPR) Setor de Ciências da Saúde. Curitiba, PR Brasil.

Contato:

Amanda de Paula Boni Navarro

E-mail:

amanda_boni@hotmail.com

Este manuscrito é baseado na dissertação de mestrado Apoio Matricial em saúde do trabalhador: a experiência do centro estadual de saúde do trabalhador do Paraná, de Amanda de Paula Boni Navarro, defendida, em 2017, na Universidade Federal do Paraná

Os autores declaram que o estudo não foi subvencionado e que não há conflitos de interesses.

Os autores informam que o trabalho não foi apresentado em eventos científicos.

\section{Apoio matricial na saúde do trabalhador no Paraná: potencialidades e desafios}

\author{
Matrix support in worker's health \\ in Paraná, Brazil: potential and challenges
}

\section{Resumo}

Introdução: as atribuições dos Centros de Referência em Saúde do Trabalhador (Cerest) estão em discussão em âmbito nacional quanto aos processos de apoio de implementação das ações de Saúde do Trabalhador no Sistema Único de Saúde (SUS). Por meio do Apoio Matricial (AM), aponta-se uma nova competência a estes equipamentos, com vistas a superar a fragmentação da Rede Nacional de Atenção Integral a Saúde do Trabalhador (Renast). Objetivo: analisar as ações de AM em Saúde do Trabalhador (ST) desenvolvidas no âmbito da Secretaria de Estado da Saúde do Paraná por meio dos Cerest. Métodos: estudo descritivo-exploratório, com abordagem qualitativa, realizado em 2016. Utilizou-se formulário eletrônico para entrevistas semiestruturadas com 35 participantes das atividades de AM em ST do estado e análise de conteúdo das informações levantadas. Resultados: verificou-se que o AM apresenta potencialidades evidenciadas pelo incremento da relação dialógica entre matriciadores e matriciados, proporcionando maior vínculo e apropriação das características dos territórios no estado. Discussão: as dificuldades identificadas consistiram na quantidade e formação das equipes, que limitam a apropriação dos pressupostos teóricos da Saúde do Trabalhador e a efetiva instituição do AM.

Palavras-chave: saúde do trabalhador; gestão em saúde; apoio matricial.

\begin{abstract}
Introduction: the duties of the Occupational Health Reference Centers (Cerest) are under discussion in Brazil regarding the support processes for the implementation of Occupational Health actions in the Unified Health System (SUS). The Matrix Support (MS) project provides a new competence to these units in order to overcome the fragmentation of the Brazilian Network of Integral Care to Workers' Health (Renast). Objective: to analyze the MS actions in Occupational Health $(\mathrm{OH})$ developed by Cerest units within the scope of the Health Department of the state of Paraná, Brazil. Methods: a descriptive, exploratory, and qualitative approach was conducted in 2016. The study applied an electronic form for semi-structured interviews with 35 participants of $M S$ activities in $\mathrm{OH}$ and content analysis of the information collected. Results: the improved dialogical relationship between matrix-assistants and matrix-assisted evidenced the MS potentiality providing a greater bond and appropriation of the characteristics of the state territories. Discussion: the difficulties identified consisted of the number and constitution of the teams, which limits the appropriation of theoretical assumptions of $\mathrm{OH}$ and the effective MS implementation.
\end{abstract}

Keywords: occupational health; health management; matrix support. 


\section{Introdução}

Neste estudo, foi focalizado o campo de atuação da Saúde do Trabalhador (ST) no âmbito da Secretaria de Estado da Saúde (Sesa) do Paraná, a qual organiza-se por meio de uma rede de Centros de Referência em Saúde do Trabalhador (Cerest). Um desses centros possui abrangência estadual, sendo sediado na capital e denominado de Centro Estadual de ST (Cest); também, compõem a rede de ST mais oito Cerest Macrorregionais (Cerest-MR), sediados em municípios considerados polos regionais do estado, congregando as 22 Regionais de Saúde (RS) e seus 399 municípios.

O CEST se constitui no espaço de gestão da ST em nível estadual e, por meio dos Cerest-MR apoia o desenvolvimento das ações na área com base na metodologia de Apoio Matricial (AM) ${ }^{1}$.

O AM está inscrito no Método Paidéia, ou Método da Roda, desenvolvido por Campos e colaboradores ao longo dos últimos 25 anos e vem sendo amplamente utilizado em políticas e práticas de saúde no Brasil ${ }^{1}$. O método visa à democratização institucional e o fortalecimento dos sujeitos e dos coleti$\operatorname{vos}^{2}$. Na ST, o AM é previsto pela Política Nacional de Atenção Integral a Saúde do Trabalhador e da Trabalhadora (PNSTT) ${ }^{3}$, publicada em 2012. Tal política preconiza que o AM deve ser desenvolvido pelos Cerest, a fim de disseminar para toda a rede de atenção do SUS a compreensão da centralidade do trabalho na determinação do processo saúde-doença ${ }^{3}$.

A implantação do AM constitui uma oportunidade de redefinição do papel dos Cerest dentro do SUS, tendo em vista a frágil articulação desses centros com a Rede de Atenção em Saúde (RAS) ${ }^{4}$ somada ao contexto de aumento das suas demandas com escassez de recursos humanos, tornando seu trabalho muito mais complexo ${ }^{5}$.

No Método Paidéia, é estabelecida uma relação de apoio entre os apoiadores matriciais (profissionais de notório saber com formações diversas em saúde) e as equipes de referência, que são compostas por profissionais de saúde coordenadores do cuidado direto de uma clientela adscrita a um serviço de saúde, de um centro de especialidades ou de equipes da Atenção Primária. Tal relação deve ser fundada em processos dialógicos de suporte assistencial e técnico-pedagógico, visando a resolução de problemas relevantes em Saúde Coletiva ${ }^{6}$.

No Paraná, o AM na ST acontece de forma diferente do que é proposto originalmente por Campos e colaboradores ${ }^{1}$. Na Sesa do Paraná, esse processo de trabalho foi instituído pelos gestores do Cest, em meados de 2011, para a gestão do trabalho em ST da seguinte forma: o Cest atua por meio da ferramenta do AM junto aos profissionais que compõem os Cerest-MR. Estes possuem como "clientes" os profissionais de saúde da RAS do SUS dos municípios das suas áreas de abrangência, conforme pode ser observado na Figura 1.

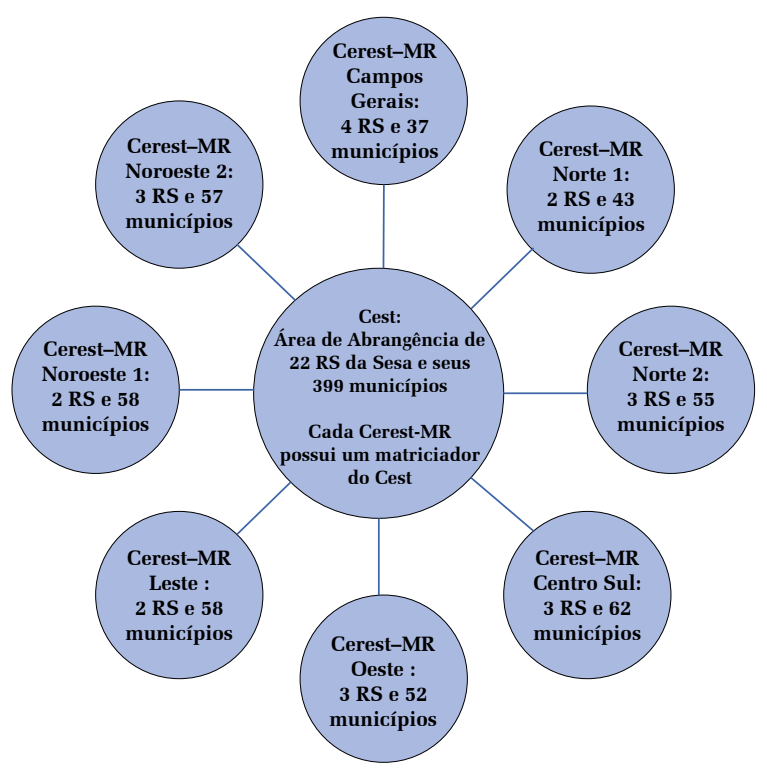

Figura 1 Apoio Matricial na Saúde do Trabalhador do estado do Paraná

Cerest-MR: Centro de Referência em Saúde do Trabalhador Macrorregional; Cest: Centro Estadual de Saúde do Trabalhador; RS: Regional de Saúde; Sesa: Secretaria de Estado da Saúde.

Tendo em vista essa forma diferenciada de aplicar o método, o objeto deste estudo foi o processo de uso do AM na gestão da política de ST no Paraná. Diante do caráter inovador da referida proposta, objetivou-se compreender e analisar as ações de AM em ST no âmbito da Sesa do Estado do Paraná, sob a perspectiva de quem apoia (matriciadores), de quem é apoiado (matriciados) e do gestor, refletindo sobre os desafios e potencialidades dessa estratégia de trabalho para a efetivação da PNSTT e da Política Estadual de Atenção Integral a Saúde do Trabalhador (Pest).

\section{Métodos}

Trata-se de estudo descritivo-exploratório, com abordagem qualitativa ${ }^{7}$, cuja pesquisa de campo ocorreu no período de abril a julho de 2016, em todos os equipamentos da ST do Paraná. O material empírico foi coletado por meio de entrevista semiestruturada autoaplicada por formulário eletrônico. O formulário foi previamente elaborado e testado com profissionais que não participaram do estudo e posteriormente enviado eletronicamente a todos os matriciados do Estado. O instrumento incluiu 
questionamentos sobre o processo de trabalho nas instituições atuantes na ST, o conceito do AM e a respeito dos seus pontos positivos e negativos. A análise de conteúdo ocorreu com base em Franco $^{8}$.

Na época do estudo atuavam na ST do estado 7 matriciadores e 50 matriciados dos 8 Cerest-RS. Apresentou-se previamente a todos esses profissionais os objetivos da pesquisa. Os critérios de inclusão utilizados foram: estar atuando no momento da pesquisa na ST da Sesa; e aceitar participar da pesquisa. Aceitaram participar um gestor, 6 matriciadores e 28 matriciados, perfazendo o total de 35 participantes.

Os preceitos éticos foram respeitados, incluindo a utilização do Termo de Consentimento Livre e Esclarecido e a não identificação dos participantes.
A pesquisa foi aprovada nos Comitês de Ética em Pesquisa da UFPR (parecer $n^{\circ} 1.412 .934$ de 2015) e da Sesa (parecer $n^{0}$ 1.472.161 de 2016). As falas dos matriciadores e do gestor foram codificadas pela letra "E", acrescidas de um número, e as respostas dos matriciados pela letra "M", sem número.

\section{Resultados e discussão}

\section{Caracterização dos participantes da pesquisa}

Destaca-se que $66 \%$ dos participantes do estudo são do sexo feminino, $40 \%$ com idades variando entre 51 a 60 anos, 68\% são especialistas, 97\% são estatutários, $40 \%$ atuam na ST entre 2 a 5 anos e $31 \%$ são Enfermeiros, como pode ser visto na Tabela 1.

Tabela 1 Características socioeconômicas dos participantes das ações de apoio matricial (n = 35) em Saúde do Trabalhador que aderiram ao estudo. Paraná, Brasil, 2016

\begin{tabular}{|c|c|c|}
\hline Variável & $n$ & $\%$ \\
\hline \multicolumn{3}{|l|}{ Sexo } \\
\hline Feminino & 23 & 66 \\
\hline Masculino & 12 & 34 \\
\hline \multicolumn{3}{|l|}{ Idade } \\
\hline De 18 a 30 anos & 1 & 3 \\
\hline De 31 a 40 anos & 8 & 23 \\
\hline De 41 a 50 anos & 12 & 34 \\
\hline De 51 a 60 anos & 14 & 40 \\
\hline \multicolumn{3}{|l|}{ Escolaridade } \\
\hline Ensino Médio/Técnico & 2 & 6 \\
\hline Graduação & 5 & 14 \\
\hline Especialização & 24 & 68 \\
\hline Mestrado & 2 & 6 \\
\hline Doutorado & 2 & 6 \\
\hline \multicolumn{3}{|l|}{ Tipo de Vínculo de Trabalho com a Sesa } \\
\hline Estatutários & 34 & 97 \\
\hline Contratados (via fundação) & 1 & 3 \\
\hline \multicolumn{3}{|l|}{ Tempo de Trabalho na ST } \\
\hline Menos de 2 anos & 4 & 11 \\
\hline Entre 2 a 5 anos & 14 & 40 \\
\hline Entre 5 a 10 anos & 11 & 31 \\
\hline Entre 10 a 20 anos & 5 & 14 \\
\hline Mais de 20 anos & 1 & 3 \\
\hline \multicolumn{3}{|l|}{ Formação Profissional } \\
\hline Outros & 11 & 31 \\
\hline Enfermagem & 11 & 31 \\
\hline Técnico em Segurança do Trabalho & 9 & 26 \\
\hline Medicina & 2 & 6 \\
\hline Farmácia & 2 & 6 \\
\hline
\end{tabular}


A partir da análise dos dados, emergiram três categorias de análise: 1) Conceituação do AM na ST e as atribuições do ato de apoiar; 2) Potencialidades do AM na ST; e 3) Desafios do AM na ST na Sesa. A seguir, serão detalhadas cada uma delas.

\section{Conceituação do AMna STe as atribuições do ato de apoiar}

A implantação do AM no Paraná ocorreu entre os anos de 2011 e 2012 para a readequação do processo de trabalho visando a implementação de um novo instrumento de gestão no estado, a Pest. Assim, os técnicos do Cest tornaram-se referências técnicas para os profissionais de cada Cerest-MR, nos diversos assuntos da ST, evidenciando-se uma mudança no processo de trabalho:

Porque antes as regionais não tinham essa referência, não sabiam com quem conversar aqui dentro. Para qualquer dúvida, ligavam para um, ligavam para outro. (E4)

Porém, alguns envolvidos mencionaram que não houve uma discussão aprofundada sobre o AM (especialmente no contexto da ST), fato que impactou na dinâmica de trabalho dos matriciadores e matriciados. Uma revisão Integrativa sobre a utilização do AM entre a Saúde Mental e a Atenção Primária em Saúde encontrou que a falta de compreensão da ferramenta constituiu um dos obstáculos para a sua implantação ${ }^{9}$. Outro estudo evidenciou que compreensões divergentes sobre a concepção do matriciamento dentro do serviço podem repercutir em diversos entendimentos das suas atribuições por parte dos profissionais ${ }^{10}$.

Contudo, foi possível extrair as concepções do AM que emergiram das práticas profissionais do próprio ato de apoiar. Corroborando com a literatura, partiu-se do pressuposto de que o apoiador aprende na prática a função e também o matriciado aprende do ato de ser apoiado ${ }^{2}$.

Sob o ponto de vista do gestor, o AM consiste nas relações interprofissionais de gestão entre matriciadores e matriciados sem processos decisórios hierarquizados entre chefias e subordinados:

\begin{abstract}
A ideia e a lógica seriam as mesmas, sendo adaptadas a um processo de gestão no Paraná para ST [...] dentro da horizontalidade, a gente poderia propor aqui uma forma de apoio, apoio técnico, e aí o político-pedagógico também [...] meu propósito era que essas pessoas (matriciadores) desenvolvessem esse lado de gestor de uma atividade, gestor de uma área da saúde pública, que passa por questões técnicas, questões pedagógicas, questões políticas, questões [...] de relação, de relacionamento, de resolução de problemas [...] e encaminhamentos da política estadual. (E1)
\end{abstract}

Nesse pronunciamento observa-se que as referências técnicas do Cest foram entendidas como Apoiadores Matriciais, visando auxiliar na gestão da ST no estado. De acordo com autores do Método Paidéia, a função apoio é de auxiliar o grupo a analisar seus dilemas e impasses, passando da análise crítica para a ação ${ }^{1,11,12}$, tal como foi apresentado na fala acima. Outros estudos consultados apontaram o AM na ST como estratégia e dispositivo de qualificação das práticas de saúde no âmbito da gestão $0^{4,13,14}$, corroborando os achados deste estudo.

Do ponto de vista dos matriciadores, o AM é uma forma de assessoria e/ou apoio técnico para os profissionais matriciados nas ações preconizadas em diretrizes nacionais e estaduais da ST, bem como auxílio na gestão dos seus processos de trabalho, conforme pode ser observado nas falas abaixo:

O matriciamento, ele facilita no gerenciamento de casos, na gerência, na gestão no caso, no nosso caso seria o município, que seria basicamente sentar com os profissionais da regional e pensar aquele território (E3);

[...] seria você estar acompanhando todos os processos de implementação da Renast. O que eu venho fazendo no meu Cerest é mais um apoio técnico na assessoria de algumas ações de ST. (E7)

Os matriciados acrescentam, além da visão de gestão do trabalho, o auxílio na resolução de problemas, troca de conhecimentos, cobrança das ações de ST e de repasse de informações, conforme pode ser observado nas seguintes falas:

Eu penso que matriciamento seja como um apoio técnico. Ou seja, uma pessoa deve estar norteando nossas ações, bem como estar sendo um intermediário entre as outras RS para que haja uma padronização de ações dentro do estado dentro da área de ST. (M)

[...] viabilizando a resolução de problemas com otimização do tempo e trazendo informações atualizadas sobre normas, leis, capacitações e campanhas a serem realizadas durante o ano, também realiza orientações sobre avaliações dos programas e pactuações realizadas em prol da ST. (M)

A partir da explicitação do conceito, os envolvidos apresentaram as atribuições do matriciamento ou do ato de apoiar, que, resumidamente, perpassam toda a implementação da Pest e da PNSTT. Achados semelhantes foram encontrados em estudo em que a troca de saberes e a capacitação apareceram como principais significados do $\mathrm{AM}^{10}$.

Destaca-se outra atribuição interessante referida pelos matriciadores:

Sempre que a gente vai, a gente acaba sendo um agente motivador, para a implementação das ações. (E7)

Esses achados da pesquisa corroboram com o Método Paidéia, no qual a função apoiador "enfatiza 
a noção de suporte, amparo, auxílio, mas também a noção de impulso ou movimento" (p. 933) ${ }^{12}$. Segundo Campos, Cunha e Figueiredo ${ }^{11}$, o método Paidéia compartilha de Vygotsky sobre o papel do professor, o qual, para além de ser um facilitador, deve apoiar ativamente o grupo em formação. Neste sentido, de acordo com Campos, Cunha e Figueiredo ${ }^{11}$, Onoko Campos afirma que há um duplo papel do apoiador: de oferecer um suporte para o grupo, valorizando seus próprios recursos e a potência dos envolvidos, ao mesmo tempo em que deve "empurrar" o grupo para atingir seus objetivos, trazendo as demandas externas e oferecendo outros recursos ${ }^{11}$.

\section{Potencialidades do AM na ST na realidade estudada}

Algumas potencialidades da ferramenta do AM na ST foram trazidas pelos envolvidos. Duas delas já foram apresentadas anteriormente: uma contida no próprio conceito/atribuição da função apoio, pelo caráter motivador do método, no sentido de ter alguém de fora do grupo trazendo sempre novas ofertas ${ }^{12}$; outra, atinente à mudança no processo de trabalho entre Cest e Cerest-MR, com o estabelecimento do contato personificado com um profissional de referência.

Em decorrência desses dois fatores destaca-se como principal potencialidade do AM, no contexto do estudo, a ampliação do vínculo entre matriciador e matriciado. A partir disso, relatou-se maior responsabilização nas questões da ST no território:

A responsabilização no sentido assim de me importar com eles e de eles poderem contar comigo na hora para qualquer trabalho, né [...] o positivo no matriciamento é dar possibilidade também de discutir essas coisas, de se aproximar mais desses profissionais que não tiveram formação para pensar nisso, né. (E3)

Com esta aproximação entre matriciadores e matriciados houve um ganho pessoal e institucional no sentido de poder desenvolver o trabalho de forma mais autônoma e de ampliação do conhecimento na área, pois o matriciador não tem a obrigação de saber tudo, mas deve conhecer a ST por completo.

Ampliou o meu olhar para a saúde do trabalhador [...] eu tenho que buscar mais coisas. Antes não, eu ficava só no sistema de informação, o resto, os outros agravos para mim eram notificação [...] então agora eu já mudei o olhar, enquanto vigilância, no meu ponto de vista, para mim como técnica foi muito bom. (E5)

Ademais, houve troca de experiências profissionais entre os envolvidos:

Quando a gente vai para as RS nas reuniões a gente escuta, a gente fica animada, então um ponto positivo é que a gente não pode parar, não pode deixar de fazer esse trabalho de capacitação, de trocas de experiências, de formação, porque é um caminho. (E7)
Por meio do AM desenvolvido pelo Cest também foi apontada pelo gestor a possibilidade de discussão da ST com outros profissionais da RAS do SUS, auxiliando na disseminação dos pressupostos da ST. Isso porque, nas reuniões de matriciamento, realizadas nas RS e nos Cerest-MR, participam profissionais de outras áreas como da Vigilância Epidemiológica e da Atenção Primária a Saúde (APS):

A gente conseguiu colocar na pauta do município [...] hoje, ninguém ignora a ST do SUS, eu acho que é um passo, a atenção primária evoluiu bastante, quem tem 13 mil e poucas notificações no ano, e para quem tinha, 6, 7 mil aí 5, 6 anos atrás, não dá para dizer que a atenção primária não evoluiu, porque senão, não teríamos notificações, então eles estão entendendo. (E1)

Especificamente do ponto de vista dos matriciados, destaca-se, na maioria das respostas, a potência do método para a melhoria da comunicação, troca de experiências exitosas em ST desenvolvidas pelas RS do estado; auxílio na resolução de problemas; qualificação das equipes municipais e o direcionamento das atividades a serem realizadas pelos Cerest-MR:

Como as RS possuem recursos humanos em quantidade insuficiente para desenvolver as suas atividades em plenitude, a função do matriciador é fundamental para dar subsídios e facilitar os trabalhos desenvolvidos pela RS e municípios, cobrar uma homogeneidade de ações entre as regionais, promover cursos e reuniões técnicas sobre saúde do trabalhador e assim inserir mais rotineiramente o desenvolvimento e a implementação de ações de interesse; (M)

É uma forma de nos deixar seguros na tomada de decisão. (M)

No âmbito da Saúde Mental, Machado e Camatta ${ }^{9}$ também encontraram como potencialidades do método a construção coletiva de saberes, a melhora da comunicação entre os trabalhadores, ampliação do conhecimento do tema por meio de encontros e trocas cotidianas entre os profissionais, e o aumento da corresponsabilização. Na relação entre especialistas e a APS, Arona ${ }^{15}$ obteve, também, como resultados da implantação do AM, a ampliação da resolubilidade das equipes, a definição do fluxo de encaminhamentos, a abertura de um canal de comunicação interprofissional e o estabelecimento de um espaço de cogestão. Tais situações convergem com os resultados desta pesquisa.

Estudos específicos sobre o uso do AM na ST tratam do seu uso entre Cerest e a APS e os resultados são positivos. O caso mais referenciado na literatura consultada é do Município de Amparo - SP, onde, por meio do AM exercido pelo Cerest Municipal às equipes da APS, se efetivou uma prática concreta de incorporação da ST na rede do SUS com intercâmbio 
sistematizado de conhecimentos e experiências entre as várias especialidades e profissões. Como facilitadores daquele processo destaca-se o matriciamento como modelo de ação pedagógica contínua e de educação permanente assumido pela equipe do Cerest, além da participação nos colegiados de gestão (pois na medida em que as ações são pactuadas em conjunto produzem mudanças duradouras nos processos de trabalho) e o protagonismo dos trabalhadores. Tais elementos foram decisivos para o compartilhamento de responsabilidades para o atendimento dos trabalhadores ${ }^{16-19}$.

\section{Desafios do AM na ST na Sesa}

Os principais desafios observados foram agrupados em duas subcategorias:

a) Dificuldades referentes a pouca apropriação do método do apoio (advindo do Método Paidéia ${ }^{11}$ )

Um dos desafios encontrados na pesquisa de campo foi o próprio ato de apoiar ou sobre a função apoio. Acredita-se que isso ocorra no serviço pela questão já apresentada anteriormente: da ausência de discussão dos pressupostos teóricos do método, uma vez que muitos matriciadores revelaram que não estão conseguindo executar o matriciamento.

Autores como Oliveira ${ }^{2}$ e Mattos ${ }^{20}$ estudaram em profundidade a função de apoio: Oliveira ${ }^{2}$ afirma que não há um só apoio e não há apoiador que se sinta pronto para apoiar. Por acreditar que a formação desta função aconteça no ato em si, é preciso ter um processo de supervisão-apoio como um espaço de compartilhamento das angústias sentidas pelos matriciadores ${ }^{2}$, fato que não ocorre no serviço estudado. Mattos complementa que a função apoio é um movimento de construção coletiva para a produção do cuidado, no qual lida-se "com afetos, encontros, desejos e abertura de sempre novas trilhas e dobras que parecem desviar e se fazer para além das políticas governamentais e de captura, é fuga e criação infinita” (p. 166) ${ }^{20}$.

Outro desafio percebido a partir da pesquisa de campo é a ausência de espaços de cogestão entre os envolvidos no serviço (entre o Cest, os Cerest-MR e o Controle Social), conforme a metodologia do apoio preconiza $^{1,11,12}$. No caso estudado o AM envolveu apenas a relação entre os profissionais de saúde.

É preciso ter esses espaços de cogestão protegidos dentro das instituições, nos quais os envolvidos se sintam seguros para refletir sobre suas práticas, configurando-se em encontros para a discussão das demandas do grupo, abrangendo desde a busca de novas informações até a elaboração de projetos de intervenção ${ }^{12}$.

Esses espaços podem ser constituídos por Colegiados de Gestão, formados pelos gestores e usuários ou apenas pelos profissionais do serviço. Podem ser espaços coletivos de caráter eventual ou permanente, no entanto, é preciso que ocorra análise sobre um tema e tomada de decisão ${ }^{1}$. Ademais, para além de espaços de discussão, parte-se do pressuposto que o trabalho em saúde é uma práxis cuja operação depende do saber acumulado pelos profissionais, e que estes devem ter autonomia e responsabilidade sanitária para construir um novo modo de agir, ou seja, "adaptar o saber tecnológico ao contexto singular” (p. 2341) ${ }^{21}$.

Para isso, é preciso que as instituições permitam este grau de autonomia. A democracia institucional depende de sistemas de cogestão instituídos pela própria organização, a fim de compartilhar os espaços de poder entre os envolvidos. Paradoxalmente, o método Paidéia se propõe a contribuir para a democratização das instituições, dependendo de que a instituição ofereça estes espaços. Tais espaços podem ser fomentados pelo apoiador institucional (outra modalidade de apoio proposta no Método Paidéia), participando de reuniões, discussões de casos, sendo uma função exercida tanto pelo gestor, quanto pode se constituir por um cargo específico ${ }^{1}$.

Documentos consultados da $\operatorname{Sesa}^{22-24}$ e estudos ${ }^{25}$ apontam uma discussão da Comissão Interinstitucional de Saúde do Trabalhador e da Trabalhadora (CISTT) sobre a necessidade da criação de um Conselho Gestor na ST do estado desde o ano de 2003.

Skamvetsakis ${ }^{26}$ aponta a experiência de um Conselho Gestor de um Cerest municipal, cujos benefícios seriam o avanço e fortalecimento de suas ações devido, em parte, à adoção da gestão colegiada, cuja composição, na época do estudo, era paritária, com representação dos movimentos sociais e gestores e trabalhadores nas reuniões ordinárias mensais.

Contrapondo a autora supracitada, Mattos afirma que "abrir espaços colegiados regionais de gestão não necessariamente significa enchê-los de potência de transformação, dependendo das intenções e apostas nesse espaço" (p. 166) ${ }^{20}$. Isso porque os trabalhadores podem não se sentir representados ou parte daquilo que se discute, além de que, tais espaços colegiados podem não garantir a democracia entre trabalhadores, gestores e usuários. Entende-se então que o desafio que se apresenta ao serviço em questão é de estruturar tais espaços de cogestão de forma institucional, caso a equipe, empoderada dos pressupostos teóricos do Método Paidéia, julgue ser pertinente.

b) Desafios referentes ao processo de trabalho do Cest e Cerest-MR

O AM surge em um contexto de escassos recursos humanos dentro da ST no estado, em todas as instâncias de gestão, fato que se reproduz até hoje. Ramos Junior ${ }^{25}$ afirma, já em 2007, que a área da ST no Paraná 
sempre apresentou um déficit de recursos humanos. No contexto nacional, em 2015, apenas 43\% dos Cerest estaduais e regionais do Brasil apresentavam as equipes mínimas completas conforme preconizado (6 profissionais de nível superior e 4 de nível médio) ${ }^{26}$.

Por conseguinte, ocorre um acúmulo de funções por parte dos matriciadores e matriciados. Somando-se a isso, devido ao fato de os Cerest-MR estarem inseridos na estrutura das RS da Sesa, os matriciados desenvolvem ações não apenas na ST, mas também nas outras vigilâncias, entre as quais a ST não é tida como prioridade:

Se eu me envolvesse só nesse matriciamento, seria o ideal, mas você não se envolve apenas no matriciamento [...] nós aqui [CEST] nos envolvemos em muitas ações. (E6)

Outra dificuldade é a própria complexidade do campo da ST, cujo trabalho exige profissionais altamente capacitados, principalmente sobre os pressupostos teóricos do campo da ST, compreendendo a centralidade do trabalho como determinante do processo saúde-doença, a determinação social da saúde e a categoria processo de trabalho como fundamental nessa determinação ${ }^{3,27,28}$.

Contudo, foram encontrados problemas na formação e no perfil profissional dos trabalhadores que estão atuando na ST, conforme ilustra o depoimento a seguir:

Há um outro ponto grave que é a falta de concepção crítica da sociedade em que vivemos, a gente pode identificar o técnico que tem uma formação crítica ao regime em que vivemos. Se ele tem uma concepção crítica da saúde coletiva, ele vai realizar as ações. E hoje, o que eu vejo: a academia não faz uma discussão desse modelo [capitalista]. (E7)

Consequentemente, o matriciador sente-se obstaculizado para propor ou pedir que os técnicos dos Cerest-MR atuem em questões específicas da área complexa que é a ST. Dificuldades de entendimento das atribuições dos Cerest são apontadas por alguns estudos ${ }^{5,20,28-31}$ devido ao próprio histórico de alterações das suas atribuições nos diversos instrumentos normativos da Renast, bem como pelas dificuldades de integração dos Cerest com os demais pontos de atenção da RAS do SUS.

Alguns estudos apontam, também, a fragilidade da Renast em processos formativos de recursos humanos na $\mathrm{ST}^{30}$ e que a composição de determinados Cerest se dá pela transferência de profissionais de outros serviços ou logo após a aprovação em concurso público, sem serem exigidas formação ou experiência na área da $\mathrm{ST}^{31}$, semelhante ao que ocorre no cenário do estudo.

Dias, Bertolini e Pimenta ${ }^{17}$ afirmam que apesar dos mais de 20 anos de história do SUS, há divergências entre o que está normatizado e o que está ocorrendo no cotidiano dos serviços, devido principalmente ao modelo político hegemônico que atende aos interesses do capital ("tensão capital-trabalho”), mesmo que em detrimento dos princípios fundamentais do SUS de universalidade e integralidade e, consequentemente, da ST.

Nessa lógica, o campo da ST apresenta suas diversas precariedades. As dificuldades encontradas neste estudo condizem com os resultados de outras pesquisas que apontam, inclusive, a ST como a área mais defasada com relação a implantação dentro do SUS devido: aos entraves políticos no âmbito municipal, o que faz com que muitos gestores não invistam no campo da vigilância; à falta de conhecimento de muitos gestores do SUS quanto à ST e o despreparo técnico de alguns profissionais de saúde (p. 139) ${ }^{17}$.

Essas dificuldades corroboram com um estudo de Neves ${ }^{5}$ sobre o papel dos Cerest no Brasil, que revelou um crescente aumento da complexidade das suas atribuições, devido ao adoecimento e mortes de trabalhadores em um contexto atual de precarização das condições de trabalho e progressivo aumento das demandas e atribuições da Renast (a exemplo do próprio AM como nova atribuição que exige destes equipamentos uma integração com a RAS do SUS nunca antes exigida). Impactando, inclusive, na saúde dos próprios trabalhadores dos Cerest.

\section{Considerações finais}

Apresentou-se a experiência particular do Paraná na utilização do AM para intermediar o processo de gestão das ações de ST entre Cest e Cerest-MR e como uma forma de organização interna do processo de trabalho. Desde a sua implantação, no final de 2011, até o término da coleta de dados, em meados de 2016, houve relativamente pouco tempo para sua “maturação”. Essa talvez se constitua em uma das maiores limitações deste estudo. Porém, foi possível observar a potência do AM nesse contexto, principalmente sobre a criação de vínculo, facilidade de comunicação, troca de experiências e como mecanismo de uniformização das ações de ST.

Sobre os desafios, foi possível identificar que eles são de duas ordens: uma, relacionada às próprias dificuldades do campo da ST no SUS, referentes à árdua tarefa dos Cerest de tentar romper as barreiras impostas pelo capitalismo para garantir, minimamente, proteção aos trabalhadores, que morrem e se acidentam gravemente; e a outra relacionada à indefinição do papel dos Cerest, ao processo e à estrutura do próprio serviço estudado, marcado pela falta do aprofundamento teórico da ferramenta e da garantia de espaços de cogestão, de recursos humanos 
adequados e suficientes, além de problemas de gestão, com mudança dos gestores impedindo a continuidade das ações, e pelo fato de a ST não ser prioridade nas agendas de saúde e serem altamente vulneráveis às ingerências políticas locais nas RS.

É possível, ao menos, tensionar o sistema de produção capitalista a romper com o ciclo de mortes e adoecimento no trabalho, por meio de um corpo técnico do
SUS robusto capacitado. Entretanto, a subordinação da vida e da saúde à necessidade do lucro só se extinguirá com a superação do modo de produção capitalista. Para isso é fundamental o entendimento de toda a sociedade sobre a centralidade do trabalho nos processos de produção de saúde e doença das coletividades humanas e do papel determinante do capitalismo na gênese do adoecimento ligado ao trabalho.

\section{Contribuições de autoria}

Navarro APB participou na elaboração do projeto e seu delineamento e no levantamento, análise e interpretação de dados. Signorelli MC e Albuquerque GSC contribuíram na análise e interpretação dos dados. Todos os autores contribuíram substancialmente na elaboração, revisão e aprovação da versão final publicada e assumem responsabilidade pública pelo seu conteúdo.

\section{Referências}

1. Campos GWS, Figueiredo MD, Pereira Júnior N, Castro CP. A aplicação da metodologia Paideia no apoio institucional, no apoio matricial e na clínica ampliada. Interface [Internet]. 2014 [citado em 23 jan 2018];18(1):983-95. https://doi.org/10.1590/180757622013.0324

2. Oliveira GN. Devir Apoiador: uma cartografia da função apoio [tese de doutorado]. Campinas: Universidade Estadual de Campinas; 2011.

3. Brasil. Ministério da Saúde. Portaria $n^{\circ} 1.823$, de 23 de agosto de 2012: institui a política nacional de saúde do trabalhador e da trabalhadora. Diário Oficial da União [Internet]. Brasília, DF; 2012 [citado em 6 set 2016];165:46. Disponível em: https://bvsms.saude.gov.br/bvs/saudelegis/gm/2012/ prt1823_23_08_2012.html

4. Dias EC, Silva TL. Contribuições da atenção primária em saúde para a implementação da política nacional de saúde e segurança no trabalho (PNSST). Rev Bras Saude Ocup [Internet]. 2013 [citado em 23 jan 2018];38(127):31-43. https://doi.org/10.1590/ S0303-76572013000100007

5. Neves IR. De centro de reabilitação a Cerest: análise de um centro de referência regional em saúde do trabalhador no interior do Mato Grosso do Sul [tese de doutorado]. São Paulo: Pontifícia Universidade Católica; 2013. 282 p.

6. Campos GWS. Equipes de referência e apoio especializado matricial: um ensaio sobre a reorganização do trabalho em saúde. Cienc Saude Colet [Internet]. 1999 [citado em 9 set 2015];4(2): 393-403. https://doi.org/10.1590/S141381231999000200013

7. Minayo MCS, Assis SG, Souza ER. Avaliação por triangulação de métodos: abordagem de programas sociais. Rio de Janeiro: Fiocruz; 2005.

8. Franco MLPB. Análise de conteúdo. Brasília, DF: Autores Associados; 2012.

9. Machado DKS, Camatta MW. Apoio matricial como ferramenta de articulação entre saúde mental e a atenção primária em saúde. Cad Saude Colet [Internet]. 2013 [citado 23 jan 2018];2(21):224-32. https://doi.org/10.1590/S1414-462X2013000200018

10. Klein AP, d’Oliveira AFPL. O “cabo de força” da assistência: concepção e prática de psicólogos sobre o Apoio Matricial no Núcleo de Apoio à Saúde da Família. Cad Saude Publica [Internet]. 2017 [citado em 23 jan 2018];33(1):e00158815. https://doi.org/10.1590/0102-311x00158815

11. Campos GWS, Cunha GT, Figueiredo MD. Práxis e formação Paidéia apoio e cogestão em saúde. São Paulo: Hucitec; 2013.

12. Figueiredo MD, Campos GWS. O apoio Paideia como metodologia para processos de formação em saúde. Interface [Internet]. 2014 [citado em 23 jan 2018];18(1):931-43. https://doi.org/10.1590/180757622013.0323

13. Chiavegatto CV, Algranti E. Políticas públicas de saúde do trabalhador no Brasil: oportunidades e desafios. Rev Bras Saude Ocup [Internet]. 2013 [citado em 6 set 2016];38(127):25-7. https://doi. org/10.1590/S0303-76572013000100005

14. Franco MS. O apoio como tecnologia para integração da vigilância em saúde com a atenção básica no âmbito municipal [dissertação]. Brasília, DF: Universidade de Brasília; 2013. 80 p.

15. Arona EC. Implantação do matriciamento nos serviços de saúde de Capivari. Saude Soc [Internet]. 2009 [citado em 23 jan 2018];18(1):26-36. https://doi.org/10.1590/S010412902009000500005

16. Santos APL. Tecendo redes, superando desafios: estudo dos processos de trabalho de casos exitosos em Saúde do Trabalhador no Sistema Único de Saúde do Estado de São Paulo [tese de doutorado]. São Paulo: Universidade Federal de São Paulo; 2010 [citado em 4 mar 2020]. Disponível em: https://repositorio.unifesp.br/handle/11600/10103

17. Dias MDA, Bertolini GCS, Pimenta AL. Saúde do trabalhador na atenção básica: análise a partir 
de uma experiência municipal. Trab Educ Saude (online) [Internet]. 2011 [citado em 23 jan 2018]; 9(1):137-148. https://doi.org/10.1590/S198177462011000100010.

18. Santos APL, Lacaz FAC. Apoio matricial em saúde do trabalhador: tecendo redes na atenção básica do SUS, o caso de Amparo/SP. Cienc Saude Colet [Internet]. 2012 [citado em 23 jan 2018]. 17(5):1143-50. https://doi.org/10.1590/S1413-81232012000500008

19. Lacaz FAC, Trapé A, Soares CB, Santos APL. Estratégia saúde da família e saúde do trabalhador: um diálogo possível. Interface [Internet]. 2013 [citado em 6 set 2016]; 17(44):75-87. https://doi. org/10.1590/S1414-32832013000100007

20. Mattos TC. A função apoio e a gestão estadual: entre encontros, afetos, trilhas, armadilhas e dobras - cartografias da saúde no Rio de Janeiro. [dissertação]. Rio de Janeiro: Escola Politécnica de Saúde Joaquim Venâncio, Fundação Oswaldo Cruz; 2013 [citado em 23 jan 2018]. Disponível em: https://www.arca.fiocruz.br/handle/icict/8621

21. Campos GWS. Cogestão e neoartesanato: elementos conceituais para repensar o trabalho em saúde combinando responsabilidade e autonomia. Cienc Saude Colet [Internet]. 2010 [citado em 23 jan 2018];15(5):2337-44. https://doi.org/10.1590/S141381232010000500009

22. Paraná. Secretaria de Estado da Saúde. Plano Estadual de Saúde 2008 - 2011 (Versão aprovada no CES - 25.09.08) [Internet]. 2008 [citado em 23 jan 2018]. Disponível em: http://www.saude.pr.gov.br/ arquivos/File/Plano_Saude_2008_2011PR_Final.pdf

23. Paraná. Secretaria de Estado da Saúde do Paraná. Conselho Estadual de Saúde. Relatório Final. $5^{\mathrm{a}}$ Conferência Estadual de Saúde do Trabalhador e da Trabalhadora do Paraná - Marcelo Montanha [Internet]. Curitiba; 2014 [citado em 9 maio 2017]. Disponível em: http://www.conselho.saude.pr.gov. $\mathrm{br} /$ modules/conteudo/conteudo.php?conteudo=211

24. Paraná. Secretaria de Estado da Saúde do Paraná. Superintendência de Vigilância em Saúde. Centro Estadual de Saúde do Trabalhador. Política Estadual de Atenção Integral à Saúde do Trabalhador do Paraná. Curitiba; 2011.

25. Ramos Junior AJ. A formação de um intelectual coletivo: um estudo sobre o percurso dos militantes na construção da saúde do trabalhador no Paraná [tese de doutorado]. Curitiba: Universidade Federal do Paraná; 2007 [citado em 23 jan 2018]. Disponível em: http:// acervodigital.ufpr.br/bitstream/handle/1884/13669/ Tese\%20de\%20Armenes\%20completa. pdf? sequence $=1 \&$ isAllowed $=y$

26. Skamvetsakis A. Gestão compartilhada e humanização em saúde do trabalhador. Bol Saude [Internet]. 2006 [citado em 23 jan 2018];20(2):15765. Disponível em: http://www.boletimdasaude. rs.gov.br/conteudo/1386/gestao-compartilhada-ehumanizacaoem-saude-do-trabalhador

27. Brasil. Ministério da Saúde. Relatório da RENAST 2016: implementação da política nacional de saúde do trabalhador e da trabalhadora: avaliação das ações desenvolvidas no período de janeiro de 2015 a março de 2016 [Internet]. Brasília, DF; 2016 [citado em 23 jan 2018]. Disponível em: https:// renastonline.ensp.fiocruz.br/sites/default/files/ arquivos/recursos/Relat\%C3\%B3rio\%20da\%20 RENAST\%202016.pdf

28. Santos AP, Lacaz FAC. Saúde do trabalhador no SUS: contexto, estratégias e desafios. In: Gomez CM, Machado JMH, Pena PGL, organizadores. saúde do trabalhador na sociedade brasileira contemporânea. Rio de Janeiro: Fiocruz; 2011.

29. Universidade Federal de Minas Gerais. Desenvolvimento de ações de Saúde do Trabalhador na Atenção Primária à Saúde: aspectos históricos, conceituais, normativos e diretrizes [Internet]. Belo Horizonte; 2010 [citado em 23 jan 2018]. Disponível em: http://renastonline.ensp. fiocruz.br/sites/default/files/arquivos/recursos/STAPS_documento\%20conceitual.pdf

30. Leão LHC, Vasconcellos LCF. Rede Nacional de Atenção Integral à Saúde do Trabalhador (Renast): reflexões sobre a estrutura de rede. Epidemiol Serv Saude [Internet]. 2011 [citado em 23 jan 2018];20(1):85-100. https://doi.org/10.5123/S167949742011000100010

31. Dias EC, Chiavegatto CV, Silva TL, Reis JC, Silva JM. Construção da RENAST em Minas Gerais: a contribuição dos CEREST, 2002-2007. Rev Med Minas Gerais [Internet]. 2010 [citado em 9 set 2015];20(2):S66-S74. Disponível em: http://rmmg.org/exportar-pdf/1036/v20n2s2a09.pdf 